\title{
FAKTOR - FAKTOR YANG BERHUBUNGAN DENGAN KEJADIAN POSTPARTUM BLUES DI KLINIK PRATAMA WILAYAH KERJA PUSKESMAS PAYUNG SEKAKI KOTA PEKANBARU
}

\author{
Ririn Ariesca ${ }^{1}$, Siska Helina ${ }^{2}$, Okta Vitriani $^{3}$ \\ *Jurusan Kebidanan Poltekkes Kemenkes Riau
}

\begin{abstract}
ABSTRAK
Angka kejadian postpartum blues dibeberapa negara seperti Jepang 15-50\%, Amerika Serikat 27\%, prancis 31,7\%, Nigeria 31,3\% dan Yunani 44,5\% (Curry, 2008). Angka kejadian postpartum blues di Asia cukup tinggi dan sangat bervariasi antara 26$85 \%$, sedangkan di Indonesia angka kejadian postpartum blues antara 50-70\% dari wanita pasca persalinan. Di Indonesia salah satunya di Provinsi Riau tepatnya di Kota Pekanbaru sekitar 16,7\%. Tujuan penelitian ini adalah untuk mengetahui faktor-faktor yang berhubungan dengan kejadian postpartum blues di Klinik Pratama Wilayah Kerja Puskesmas Payung Sekaki Kota Pekanbaru Tahun 2017. Penelitian ini dilaksanakan di 3 Klinik Pratama yang di Wilayah Kerja Puskesmas Payung Sekaki pada bulan September 2016 s/d Juli 2017. Sampel penelitian ini adalah 45 orang ibu postpartum di 3 Klinik Pratama yang diambil secara accidental sampling. Jenis penelitian ini adalah survey analitik dengan desain penelitian cross sectional. Analisa data dilakukan secara univariat dan bivariat dengan menggunakan uji chi square dan dengan bantuan komputerisasi. Hasil penelitian ini menunjukkan bahwa dari 45 orang ibu postpartum terdapat 12 orang $(26,7 \%)$ ibu yang mengalami postpartum blues dan 33 orang $(73,3 \%)$ yang tidak mengalami postpartum blues. Hasil penelitian ini juga menunjukkan adanya hubungan antara umur ( $p$ $=0,007)$, dan paritas $(p=0,001)$ dengan kejadian postpartum blues serta menunjukkan tidak adanya hubungan antara jenis persalinan $(p=0,933)$, penghasilan $(p=1,000)$ dan kesiapan menjadi ibu $(p=1,000)$ dengan kejadian postpartum blues. Saran kepada tenaga kesehatan yaitu deteksi atau screening adanya kemungkinan terjadinya postpartum blues kepada semua ibu postpartum dan jadikan screening tersebut menjadi bagian dari pengkajian tetap pada ibu postpartum.
\end{abstract}

Kata kunci : postpartum blues, umur, paritas

Daftar pustaka : 31 (2000-2016)

\section{PENDAHULUAN}

Melahirkan merupakan suatu peristiwa penting yang dinantikan oleh sebagian besar wanita karena membuat mereka menjadi seorang wanita yang telah berfungsi utuh dalam kehidupan. Menjadi orang tua merupakan suatu krisis tersendiri bagi wanita karena mereka harus mampu melewati masa transisi. Secara psikologis seorang wanita akan merasakan tanda dan gejala psikiatrik setelah melahirkan. Seorang wanita postpartum membutuhkan penyesuaian dalam menghadapi aktivitas dan peran barunya, sebagai seorang ibu pada minggu-minggu pertama setelah melahirkan baik fisik maupun psikis. Beberapa wanita postpartum berhasil menyesuaikan diri dengan baik, tetapi wanita postpartum lainnya yang tidak berhasil menyesuaikan diri dan mengalami gangguan-gangguan 
psikologis yang lebih dikenal dengan istilah postpartum blues (Mansur, 2009).

Postpartum blues adalah suasana hati yang berlangsung selama 3-6 hari pasca melahirkan (Cunninghum, 2006). Postpartum blues adalah kondisi yang sering terjadi dalam 14 hari pertama setelah melahirkan dan cenderung lebih buruk pada hari ketiga dan keempat (Suririnah, 2008). Postpartum bluesadalah perasaan sedih yang dialami oleh ibu setelah melahirkan dan juga berkaitan dengan bayinya (Ambarwati, 2009).

Angka kejadian postpartum blues dibeberapa negara seperti Jepang 15$50 \%$, Amerika Serikat 27\%, Prancis $31,7 \%$, Nigeria $31,3 \%$ dan Yunani 44,5\% (Curry, 2008). Angka kejadian postpartum blues di Asia cukup tinggi dan sangat bervariasi antara 26-85\%, sedangkan di Indonesia angka kejadian postpartum blues antara $50-70 \%$ dari wanita pasca persalinan (Ibrahim dkk, 2012).

Di Indonesia beberapa penelitian sudah dilakukan tentang postpartum blues salah satunya di provinsi Riau tepatnya di kota Pekanbaru sekitar 16,7\% ibu postpartum dengan postpartum blues (Misrawati dkk, 2014). Hasil penelitian Desfanita dkk, 2015 didapatkan hasil sebagian besar ibu mengalami kejadian postpartum blues sebanyak 40 responden $(53,3 \%)$.

Pasca melahirkan dalam 24 jam, kadar estrogen dan hormon kelenjar gondok turun secara drastis. Gangguan keseimbangan hormon ini menimbulkan gejala-gejala seperti: menangis, mengalami perubahan perasaan, cemas, khawatir mengenai sang bayi, kesepian, kurang percaya diri menjadi seorang ibu (Mansur, 2009).

Ibu postpartum blues yang tidak berhasil menyesuaikan diri dengan peran barunya akan mengalami gangguan emosional seperti depresi pascapersalinan (DPP). Faktor yang mempengaruhi terjadinya postpartum blues yang apabila tidak ditangani akan menjadikan Depresi Postpartum, secara internal adalah umur ibu ketika menikah dan hamil $<20$ tahun atau $>35$ tahun, pertama kali melahirkan/ primipara, kesiapan menerima anggota keluarga baru atau kesiapan menjadi ibu termasuk pengetahuan atau keterampilan merawat bayi dan pendidikan. Aspek eksternal adalah dukungan keluarga, dukungan suami, budaya/ kebiasaan masyarakat terkait persalinan, status ekonomi, informasi asuhan nifas dan riwayat asuhan nifas (Bobak, 2005).

Kesiapan menyambut kehamilan dicerminkan dalam kesiapan dan respon emosionalnya dalam menerima kehamilan. Kesiapan menjadi ibu juga dipersiapkan saat hamil (Bobak, 2005). Kesiapan menjadi ibu harus meningkatkan atau keadaan yang harus dicapai dalam proses perkembangan terutama mental, fisiknya, sosial dan emosional (Hamalik, 2008).

Penyebab postpartum blues belum diketahui secara pasti. Faktor terjadinya postpartum blues adalah pengalaman kehamilan dan persalinan, faktor psikososial, dan faktor spiritual. Pengalaman kehamilan dan persalinan $(38,71 \%)$, faktor psikososial $(19,35 \%)$, dari kualitas dan kondisi bayi $(16,13 \%)$ dan faktor spiritual $(9,78 \%)$ (Setyowati, 2006). Apabila kejadian postpartum blues ini tidak ditangani maka akan berlanjut menjadi depresi postpartum. Dampak dari depresi postpartumini dapat menurunkan semangat hidup bahkan sampai pada tindakan bunuh diri. (Soep, 2009).

Berdasarkan hasil penelitian Wijayanti (2013), faktor - faktor yang mempengaruhi postpartum blues adalah sosial ekonomi, paritas, tingkat pendidikan, umur. Berdasarkan penelitian Desfanita $\mathrm{dkk}(2015)$ faktor-faktor yang mempengaruhi postpartum blues adalah persalinan sectio caesarea dan kesiapan kehamilan, tingkat pendidikan, umur responden yaitu remaja akhir.

Berdasarkan hasil survey saat dinas kemarin ada didapatkan beberapa ibu 
yang mengalami tanda dan gejala postpartum blues pada minggu pertama setelah melahirkan. Namun bidan tidak menyadari bahwa tanda dan gejala tersebut adalah tanda postpartum blues. Beberapa tahun yang lalu ada kejadian ibu postpartum mengalami depresi dan mengakhiri hidupnya dengan membunuh dirinya sendiri. Setelah ditelusuri penyebabnya adalah tidak ada dukungan dari suaminya pada saat melahirkan anaknya.

Maka berdasarkan latar belakang tersebut peneliti tertarik untuk melakukan penelitian tentang "Faktor - faktor yang berhubungan dengan kejadian Postpartum Bluesdi Klinik Pratama Wilayah Kerja Puskesmas Payung Sekaki Kota Pekanbaru Tahun 2017 “

\section{METODE PENELITIAN}

Jenis penelitian survey analitik dengan desain cross sectional. Penelitian dilaksanakan pada bulan September 2016 sampai Juli 2017 di Klinik Pratama Wilayah Kerja Puskesmas Payung Sekaki Kota Pekanbaru. Populasi adalah ibu postpartum di Klinik Pratama Wilayah Kerja Puskesmas Payung Sekaki yang berjumlah 45 orang dan sampel diambil secara accidental sampling. Pengolahan data dilakukan secara komputersasi dengan analisa data univariat dan bivariat menggunakan uji statistik Chi Square.

\section{HASIL PENELITIAN}

\section{Analisa Univariat}

Tabel 1 Distribusi Frekuensi Kejadian Postpartum Blues pada Ibu Postpartum di Klinik Pratama Wilayah Kerja Puskesmas Payung Sekaki Kota Pekanbaru

\begin{tabular}{cccc}
\hline No & $\begin{array}{c}\text { Postpartum } \\
\text { Blues }\end{array}$ & (f) & (\%) \\
\hline $\mathbf{1}$ & $\begin{array}{c}\text { Postpartum } \\
\text { Blues } \\
\text { Tidak }\end{array}$ & 12 & 26,7 \\
$\mathbf{2}$ & $\begin{array}{c}\text { Postpartum } \\
\text { Blues }\end{array}$ & 33 & 73,3 \\
\hline
\end{tabular}

\begin{tabular}{ccc}
\hline Jumlah & 45 & 100 \\
\hline sumber:data primer & Maret-Juni 2017
\end{tabular}

Tabel 2 Distribusi Frekuensi Umur Ibu Postpartum di Klinik Pratama Wilayah Kerja Puskesmas Payung Sekaki Kota Pekanbaru

\begin{tabular}{clcc}
\hline No & \multicolumn{1}{c}{ Umur } & (f) & (\%) \\
\hline $\mathbf{1}$ & $\begin{array}{l}\text { Berisiko } \\
(<20 \text { atau }>35 \\
\text { tahun })\end{array}$ & 26 & 57,8 \\
$\mathbf{2}$ & $\begin{array}{l}\text { Tidak berisiko } \\
(20-35 \text { tahun })\end{array}$ & 19 & 42,2 \\
& Jumlah & 45 & 100 \\
\hline
\end{tabular}

Sumber: data primer Maret-Juni 2017

Tabel 3 Distribusi Frekuensi Paritaspada Ibu Postpartum di Klinik Pratama Wilayah Kerja Puskesmas Payung Sekaki Kota Pekanbaru

\begin{tabular}{cccc}
\hline No & Paritas & $\begin{array}{c}\text { Frekuensi } \\
\text { (f) }\end{array}$ & $\begin{array}{c}\text { Persentase } \\
(\boldsymbol{\%})\end{array}$ \\
\hline 1 & Primipara & 22 & 48,9 \\
2 & Multipara & 23 & 51,1 \\
\multicolumn{2}{c}{ Jumlah } & 45 & 100 \\
\hline \multicolumn{2}{l}{ Sumber: data primer Maret - Juni 2017 }
\end{tabular}

Tabel 4 Distribusi Frekuensi Jenis Persalinan pada Ibu Postpartum di Klinik Pratama Wilayah Kerja Puskesmas Payung Sekaki Kota Pekanbaru

\begin{tabular}{|c|c|c|c|}
\hline No & $\begin{array}{c}\text { Jenis } \\
\text { Persalinan }\end{array}$ & (f) & $(\%)$ \\
\hline 1 & $\begin{array}{c}\text { Persalinan } \\
\text { dengan } \\
\text { bantuan }\end{array}$ & 9 & 20 \\
\hline \multirow[t]{2}{*}{2} & $\begin{array}{c}\text { Persalinan } \\
\text { normal }\end{array}$ & 36 & 80 \\
\hline & Jumlah & 45 & 100 \\
\hline
\end{tabular}

Sumber: data primer Maret-Juni 2017

Tabel 5 Distribusi Frekuensi Penghasilan pada Ibu Postpartum di Klinik Pratama Wilayah Kerja 
Puskesmas

Payung Sekaki Kota Pekanbaru

\begin{tabular}{cccc}
\hline No & Penghasilan & (f) & $(\boldsymbol{\%})$ \\
\hline 1 & <UMR & 28 & 62,2 \\
2 & $>$ UMR & 17 & 37,8 \\
& Jumlah & 45 & 100 \\
\hline
\end{tabular}

Sumber: data primer Maret-Juni 2017

Tabel 6 Distribusi Frekuensi Kesiapan Menjadi Ibu pada Ibu Postpartum di Klinik Pratama Wilayah Kerja Puskesmas Payung Sekaki Kota Pekanbaru

Sumber: data primer Maret-Juni 2017

\section{Analisa Bivariat}

Tabel 7Hubungan Umur Ibu dengan Kejadian Postpartum Blues pada Ibu Postpartum di Klinik Pratama Wilayah Kerja Puskesmas Payung Sekaki Kota Pekanbaru

\begin{tabular}{|c|c|c|c|c|c|c|c|}
\hline \multirow[t]{2}{*}{$\begin{array}{l}\mathbf{N} \\
\mathbf{o}\end{array}$} & \multirow[t]{2}{*}{$\begin{array}{l}\text { Umur } \\
\text { Ibu }\end{array}$} & \multicolumn{2}{|c|}{$\begin{array}{l}\text { Postpartum } \\
\text { blues }\end{array}$} & \multicolumn{2}{|c|}{$\begin{array}{c}\text { Tdk } \\
\text { postpartum } \\
\text { blues }\end{array}$} & \multirow[t]{2}{*}{ Total } & \multirow[t]{2}{*}{$\mathbf{P}$} \\
\hline & & $\mathbf{n}$ & $\%$ & n & $\%$ & & \\
\hline 1 & $\begin{array}{c}<20 \text { atau } \\
>35\end{array}$ & 11 & 42,3 & 15 & 57,7 & 26 & \\
\hline 2 & $20-35$ & 1 & 5,3 & 18 & 94,7 & 19 & 0,007 \\
\hline & umlah & 12 & 26,7 & 33 & 73,3 & 45 & \\
\hline
\end{tabular}

Sumber: data primer Maret-Juni 2017

Tabel 8Hubungan Paritas Ibu dengan Kejadian Postpartum Blues pada Ibu Postpartum di Klinik Pratama Wilayah Kerja Puskesmas Payung Sekaki Kota Pekanbaru
Sumber: data primer Maret-Juni 2017

Tabel 9 Hubungan Jenis Persalinan Ibu dengan Kejadian Postpartum Blues pada Ibu Postpartum di Klinik Pratama Wilayah Kerja Puskesmas Payung Sekaki Kota Pekanbaru

Sumber: data primer Maret-Juni 2017

Tabel 10 Hubungan Penghasilan Ibu dengan Kejadian Postpartum Blues pada Ibu Postpartum di Klinik Pratama Wilayah Kerja Puskesmas Payung Sekaki Kota Pekanbaru

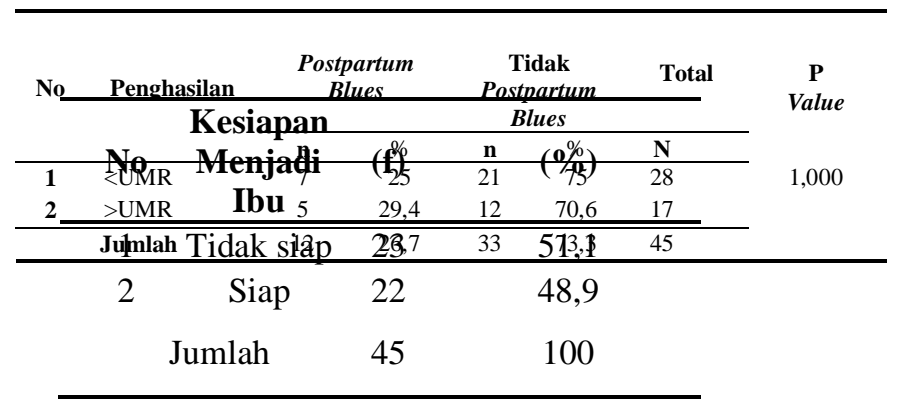

\begin{tabular}{|c|c|c|c|c|c|c|c|}
\hline \multirow[t]{2}{*}{ No } & \multirow[t]{2}{*}{ Jenis Persalinan } & \multicolumn{2}{|c|}{$\begin{array}{c}\text { Postpartum } \\
\text { Blues }\end{array}$} & \multicolumn{2}{|c|}{$\begin{array}{l}\text { Tdk } \\
\text { postpartum } \\
\text { blues }\end{array}$} & \multirow{2}{*}{$\begin{array}{l}\text { Total } \\
\mathbf{n} \\
\end{array}$} & \multirow[t]{2}{*}{$\begin{array}{c}\mathbf{P} \\
\text { value }\end{array}$} \\
\hline & & $\mathbf{n}$ & $\%$ & $\mathbf{n}$ & $\%$ & & \\
\hline 1 & $\begin{array}{l}\text { Persalinan } \\
\text { dengan bantuan }\end{array}$ & 3 & 33,3 & 6 & 66,7 & 9 & 0,933 \\
\hline 2 & $\begin{array}{l}\text { Persalinan } \\
\text { normal }\end{array}$ & 9 & 25 & 27 & 75 & 36 & \\
\hline & Jumlah & 12 & 26,7 & 33 & 73,3 & 45 & \\
\hline
\end{tabular}

Sumber: data primer Maret-Juni 2017

Tabel 11 Hubungan Kesiapan Menjadi Ibu dengan Kejadian Postpartum Blues pada Ibu Postpartum di Klinik Pratama Wilayah Kerja Puskesmas Payung Sekaki Kota Pekanbaru

\begin{tabular}{|c|c|c|c|c|c|c|c|}
\hline \multirow[t]{2}{*}{ No } & \multirow[t]{2}{*}{$\begin{array}{c}\text { Kesiapan } \\
\text { menjadi Ibu }\end{array}$} & \multicolumn{2}{|c|}{$\begin{array}{l}\text { Postpartum } \\
\quad \text { Blues }\end{array}$} & \multicolumn{2}{|c|}{$\begin{array}{c}\text { Tidak } \\
\text { Postpartum } \\
\text { Blues } \\
\end{array}$} & \multirow{2}{*}{$\begin{array}{c}\text { Total } \\
\mathbf{N} \\
\end{array}$} & \multirow[t]{2}{*}{$\begin{array}{c}\mathrm{P} \\
\text { Valeu }\end{array}$} \\
\hline & & f & $\%$ & $\mathbf{F}$ & $\%$ & & \\
\hline 1 & Siap & 6 & 27,3 & 16 & 72,7 & 22 & \multirow{3}{*}{1,000} \\
\hline 2 & tidak siap & 6 & 26,1 & 17 & 73,9 & 23 & \\
\hline & Jumlah & 12 & 26,6 & 33 & 73,3 & 45 & \\
\hline
\end{tabular}

\section{PEMBAHASAN}

Hubungan Umur Ibu dengan Kejadian Postpartum Blues 
Hasil analisa hubungan umur ibu dengan kejadian postpartum blues di Klinik Pratama Wilayah Kerja Puskesmas Payung Sekaki menunjukkan hasil bahwa dari 45 responden, didapatkan hasil bahwa kelompok yang usia berisiko $<20$ atau >35 tahun yaitu sebanyak 11 responden $(42,3 \%)$ yang terjadi postpartum blues dan kelompok usia yang tidak beresiko 20-35 tahun sebanyak 1 responden $(5,3 \%)$ yang terjadi postpartum blues. Hasil uji Chi Square diperoleh $\mathrm{p}$ value $=0,007$ lebih kecil dari nilai $\alpha=0,05$, sehingga hipotesa Ho ditolak atau ada hubungan antara umur dengan kejadian postpartum blues di Klinik Pratama Wilayah Kerja Puskesmas Payung Sekaki.

Hasil penelitian ini sesuai dengan penelitian yang dilakukan oleh Yuliana dan Irawati (2013) menyatakan bahwa kejadian postpartum blues lebih banyak dialami oleh wanita yang berusia <20 tahun atau > 35 tahun (81,8\%). Hasil penelitian Khotimah, H (2014) menyatakan bahwa kejadian postpartum blues sebanyak $(54,5 \%)$.

Hasil yang ditemukan dilapangan ada 1 responden yang termasuk di kelompok umur 20-35 yang mengalami kejadian postpartum blues dikarenakan beberapa faktor yang mempengaruhi ibu postpartum tersebut diantaranya adalah penghasilan dan kesiapan menjadi ibu. Ibu mengatakan 1 tahun ini usahanya mengalami bangkrut. Jadi, penghasilan keluarga berkurang dan kadang tidak cukup untuk kebutuhan sehari-hari. Selain itu ibu juga mengatakan pada anak pertama orang tua ibu masih ada dan mengurus anak pertama dari lahir sampai 4 tahun tetapi pada anak kedua ini orang tua ibu sudah tidak ada dan ibu harus mengurus anak sendiri dan ibu kesusahan mengurus bayinya. Sehingga ibu kadang tiba-tiba merasa sedih sendiri dan kadang menangis saat merawat bayinya.

\section{Hubungan Paritas dengan Kejadian Postpartum blues}

Hasil analisa hubungan paritas ibu dengan kejadian postpartum blues di Klinik Pratama Wilayah Kerja Puskesmas Payung Sekaki menunjukkan hasil bahwa dari 45 responden, didapatkan bahwa ibu primipara yang mengalami postpartum blues adalah sebanyak 11 responden (50\%) dan ibu multipara juga ada yang mengalami postpartum blues yaitu sebanyak 1 responden (4,3\%). Hasil uji Chi Square diperoleh $\mathrm{p}$ value $=0,001$ lebih kecil dari nilai $\alpha=0,05$, sehingga hipotesa Ho ditolak atau ada hubungan antara umur dengan kejadian postpartum blues di Klinik Pratama Wilayah Kerja Puskesmas Payung Sekaki.

Penelitian ini sesuai dengan Ibrahim (2012) yang menunjukkan bahwa yang paling banyak mengalami depresi adalah primipara (30,8\%). Penelitian yang dilakukan Khotimah, H (2014) menyatakan bahwa hampir primipara mengalami kejadian postpartum blues $(27,3 \%)$.

Dari hasil penelitian yang didapat, primipara lebih berisiko terkena dampak postpartum blues karena belum berpengalaman dalam merawat anak, sehingga merasa menghadapi masalah sendiri. Membutuhkan orang-orang yang mendampingi dalam masa nifas, sehingga masa nifas akan dilewati dengan baik. Namun, ada 1 ibu multipara yang mengalami postpartum blues dikarenakan ibu belum berpengalaman dalam merawat bayinya. ibu mengatakan pada anak pertama orang tuanya yang merawat bayi mulai dari lahir sampai beberapa tahun. Pada anak kedua ini orang tua ibu sudah tidak ada jadi ibu harus merawat bayinya sendiri.

\section{Hubungan Jenis Persalinan dengan Kejadian Postpartum Blues}

Hasil analisa hubungan jenis persalinan ibu dengan kejadian postpartum blues di Klinik Pratama Wilayah Kerja Puskesmas Payung Sekaki menunjukkan hasil bahwa dari 45 responden, didapatkan hasil bahwa ibu yang persalinan normal lebih cenderung 
mengalami postpartum blues adalah sebanyak 11 responden $(25 \%)$ dari 36 responden yang persalinan normal dan ibu yang persalinannya dengan bantuan hanya 3 responden $(33,3 \%)$ dari 9 responden yang persalinannya dengan bantuan. Hasil uji Chi Square diperoleh p value $=0,933$ lebih besar dari nilai $\alpha=$ 0,05, sehingga hipotesa Ho diterima atau tidak ada hubungan antara jenis persalinan dengan kejadian postpartum blues di Klinik Pratama Wilayah Kerja Puskesmas Payung Sekaki. Hal ini karena kesiapan menjadi ibu sudah baik, status ekonomi baik, dan berpengalaman dalam merawat bayinya membuat ibu dapat menyesuaikan diri dengan keadaan setelah melahirkan sehingga tidak menyebabkan terjadinya gangguan psikologis.

Hasil penelitian ini sesuai dengan penetian Desfanita dkk (2015) yang menyatakan $p$ valeulebih besar dari nilai $\alpha$ sehingga tidak ada hubungan antara jenis persalinan dengan kejadian postpartum blues. Jenis penelitian ini juga sesuai dengan penelitian Cury, et al., (2008) yang menyatakan bahwa komplikasi yang dialami ibu selama periode intranatal tidak berhubungan dengan terjadinya postpartum blues.

Menurut penelitian Desfanita, dkk (2015) mendapatkan hasil uji Chi Square diperoleh $p$ value $=0,185$ lebih besar dari nilai $\alpha$ yang artinya tidak ada hubungan antara jenis persalinan dengan kejadian postpartum blues. Menurut penelitian Ibrahim, dkk (2012) mendapatkan hasil bahwa depresi postpartum sebagian besar terdapat pada jenis persalinan patologis (caesarea), sebanyak 46,7\% responden, sedangkan pada persalinan normal hanya $2,2 \%$ responden.

Dari hasil peneliti didapatkan bahwa ibu dengan persalinan dengan bantuan (SC) terdapat 3 responden yang mengalami postpartum blues. Ini juga dipengaruhi oleh beberapa faktor seperti umur, paritas dan kesiapan menjadi ibu. Dari 3 responden ini hanya 1 responden yang belum siap menjadi ibu. Ini dikarenakan umur ibu yang kurang dari 20 dan baru anak pertama disini ibu juga mengatakan kurang dukungan dari suami sehingga ibu terkadang sedih sendiri dan kadang-kadang menangis.

\section{Hubungan Penghasilan dengan Kejadian Postpartum Blues}

Hasil analisa hubungan penghasilan ibu dengan kejadian postpartum blues di Klinik Pratama Wilayah Kerja Puskesmas Payung Sekaki menunjukkan hasil bahwa dari 45 responden, didapatkan hasil bahwa status ekonomi yang kurang mengalami postpartum blues sebanyak 7 responden $(25 \%)$ dari 28 responden dan responden yang status ekonomi baik mengalami postpartum blues sebanyak 5 responden (29,4\%). Hasil uji Chi Square diperoleh $\mathrm{p}$ value $=1,000$ lebih besar dari nilai $\alpha=0,05$, sehingga hipotesa $\mathrm{Ho}$ gagal ditolak atau tidak ada hubungan antara penghasilan dengan kejadian postpartum blues di Klinik Pratama Wilayah Kerja Puskesmas Payung Sekaki.

Penelitian ini tidak sesuai dengan penelitian yang dilakukan Ibrahim (2012) yang menyatakan bahwa depresi postpartum sebagian besar terdapat pada responden yang memiliki status ekonomi kurang (37,9\%). Hasil penelitian ini tidak sesuai dengan penelitian, Ibrahim. F, dkk, 2012) bahwa pendapatan yang rendah berkontribusi terhadap terjadinya postpartum blues.

Penelitian ini sesuai dengan penelitian Dian Irawati (2013) menyatakan bahwa tidak terdapat hubungan yang signifikan antara pendapatan dengan kejadian postpartum blues dengan nilai $\mathrm{p}=0,182$. Penelitian ini sesuai dengan penelitian Khusnul Azmi (2016) menyatakan bahwa hasil analisis bivariat secara statistik variabelekonomi tidak berhubungan dengan depresi pada ibu postpartum dengan nilai $p$ value $0,376(\mathrm{p}<0,05)$.

Dari beberapa penelitian diatas mengatakan sosial ekonomi tidak mempunyai hubungan dengan kejadian 
postpartum blues. Hal ini dikarenakan keluarga mampu mengatasi pengeluaran untuk biaya perawatan ibu selama persalinan, serta tambahan dengan hadirnya bayi baru lahir ini mungkin hampir tidak merasakan beban keuangan sehingga tidak terganggu proses transisi menjadi rombungan,

Dari hasil penelitian ibu yang ekonominya baik tetapi ada yang mengalami postpartum blues dikarenakan oleh beberapa faktor yaitu faktor umur ibu, jumlah anak, jenis persalinan yang ibu lalui dan kesiapan menjadi ibu.

\section{Hubungan Kesiapan Menjadi Ibu dengan Kejadian Postpartum Blues}

Hasil analisa hubungan kesiapan menjadi ibu dengan kejadian postpartum blues di Klinik Pratama Wilayah Kerja Puskesmas Payung Sekaki menunjukkan hasil bahwa dari 45 responden, didapatkan hasil bahwa jumlah responden yang siap menjadi ibu yaitu 6 dan yang belum siap menjadi ibu yaitu sebanyak 6 responden. Hasil uji Chi Square diperoleh $\mathrm{p}$ value $=1,000$ lebih besar dari nilai $\alpha=0,05$, sehingga hipotesa Ho gagal ditolak atau tidak ada hubungan antara kesiapan menjadi ibu dengan kejadian postpartum blues di Klinik Pratama Wilayah Kerja Puskesmas Payung Sekaki.

Kesiapan menjadi ibu dimulai dari kesiapan menyambut kehamilan dicerminkan dalam kesiapan dan respon emosionalnya dalam menerima kehamilan. Seorang wanita memandang kehamilannya sebagai suatu hasil alami hubungan perkawinan, baik yang diinginkan maupun tidak diinginkan, tergantung dengan keadaan. Sebagai wanita lain menerima kehamilan sebagai kehendak alam dan bahkan pada beberapa wanita termasuk banyak remaja, kehamilan merupakan akibat percobaan seksual tanpa menggunakan kontrasepsi. Awalnya mereka terkejut ketika tahu bahwa dirinya hamil, namun sering waktu mereka akan menerima kehadiran seorang anak (Bobak, 2005).
Hasil penelitian ini tidak sesuai dengan penelitian yang dilakukan Desfanita, dkk (2015) yang menyatakan tidak siap menjadi ibu cendrung mengalami postpartum blues $(91,2 \%)$. Menurut penelitian ini ibu yang tidak siap menjadi ibu sebanyak 6 responden mengalami postpartum blues dan terjdi karena beberapa faktor, seperti umur ibu, paritas, penghasilan dan jenis persalinan yang ibu lalui.

\section{KESIMPULAN}

a. Ibu postpartum yang mengalami postpartum blues di Klinik Pratama Wilayah Kerja Puskesmas Payung Sekaki selama bulan Maret- Juni 2017 adalah sebanyak 12 responden $(26,7 \%)$.

b. Frekuensi umur ibu postpartum di Klinik Pratama Wilayah Kerja Puskesmas Payung Sekaki adalah sebanyak 26 responden $(57,8 \%)$ berumur $<20$ atau $\geq 35$ tahun dan 19 responden $(42,2 \%)$ yang berumur 20 35 tahun.

c. Frekuensi paritas ibu postpartum di Klinik Pratama Wilayah Kerja Puskesmas Payung Sekaki adalah sebanyak 22 responden $(48,9 \%)$ yang primipara dan 23 responden $(51,1 \%)$ yang multipara.

d. Frekuensi jenis persalinan ibu postpartum di Klinik Pratama Wilayah Kerja Puskesmas Payung Sekaki adalah sebanyak 9 responden (20\%) yang persalinannya dengan bantuan dan 36 responden (80\%) yang persalinannya normal.

e. Frekuensi penghasilan di dalam keluarga ibu postpartum di Klinik Pratama Wilayah Kerja Puskesmas Payung Sekaki adalah sebanyak 28 responden $(62,2 \%)$ yang penghasilan didalam keluarga <UMR dan 17 responden $(37,8 \%)$ yang penghasilan didalam keluarga $>$ UMR.

f. Frekuensi kesiapan menjadi ibu pada ibu postpartum di Klinik Pratama Wilayah Kerja Puskesmas Payung 
Sekaki adalah 23 responden $(51,1)$ yang belum siap menjadi ibu dan 22 responden $(48,9 \%)$ yang siap menjadi ibu.

g. Ada hubungan antara umur ibu dengan kejadian postpartum blues di Klinik Pratama Wilayah Kerja Puskesmas Payung Sekaki dengan $\mathrm{p}=0,007$.

h. Ada hubungan antara paritas dengan kejadian postpartum blues di Klinik Pratama Wilayah Kerja Puskesmas Payung Sekaki dengan $\mathrm{p}=0,001$

i. Tidak ada hubungan antara jenis persalinan dengan kejadian postpartum blues di Klinik Pratama Wilayah Kerja Puskesmas Payung Sekaki dengan $\mathrm{p}=0,933$

j. Tidak ada hubungan antara penghasilan dengan kejadian postpartum blues di Klinik Pratama Wilayah Kerja Puskesmas Payung Sekaki dengan $\mathrm{p}=1,000$

k. Tidak ada hubungan antara kesiapan menjadi ibu dengan kejadian postpartum blues di Klinik Pratama Wilayah Kerja Puskesmas Payung Sekaki dengan $\mathrm{p}=1,000$

\section{SARAN}

\section{a. Bagi Instansi Pendidikan}

Dapat dijadikan masukan untuk pengembangan pendidikan serta sebagai bahan bacaan yang dapat menambah referensi perpustakaan, dan dapat dijadikan masukan untuk meningkatkan mutu program-program kesehatan

\section{b. Bagi Tenaga Kesehatan}

Deteksi dini atau screening adanya kemungkinan terjadinya postpartum blues sebaiknya bagian dari pengkajian tetap pada ibu postpartum. Jadi semua ibu pasca melahirkan dikaji status psikologisnya dengan menggunakan skala EPDS.

\section{c. Bagi Peneliti Selanjutnya}

Diharapkan hasil penelitian ini menjadi bahan perbandingan dan masukan bagi peneliti selanjutnya dan diharapkan peneliti selanjutnya dapat menambah variabel-variabel yang lainnya.

\section{DAFTARPUSTAKA}

Ambarwati, E.R.Diah. W. 2010.Asuhan Kebidanan Nifas. Yogyakarta : Nuha Medika

Bobak, I.M. Lowdermilk, D.L.\& Jensen, M.D. 2005. Buku Ajar Maternitas. Jakarta : EGC

Cunninghum, F.G. 2006. Obstetri Williams. Jakarta : EGC

Cury, A.F dkk. 2008. Maternity "Blues": Prevalence and Risk Factors. The Spanish Journal of Psychology 2008, Vol. 11, No. 2, 593-599. http://revistas.ucm.es/ $\quad[10$ januari 2017]

Desfanita, dkk. 2015. Faktor -Faktor Yang Mempengaruhi Postpartum Blues. http://jom.unri.ac.id/ .[17 oktober 2016]

Hamalik, O. 2008. Kurikulum dan Pembelajaran. Jakarta : Sinar Grafika Henderson, C. 2005. Buku Ajar Konsep Kebidanan. Jakarta :EGC

Ibrahim, Fatmah. Rahmah. Ikhsan, M. 2012. Faktor-Faktor Yang Berhubungan Dengan Depresi Postpartum di RSIA Pertiwi Makassar.http://repository.unhas.ac.i d/. [17 oktober 2016]

Khotimah, H. 2014. Usia Dan Paritas Dengan Postpartum Blues di RSUD Bangil Pasuruan. http://repository.poltekkesmajapahit.a c.id/.[19 oktober 2016]

Mansur, H. 2009. Psikologi Ibu Dan Anak Untuk Kebidanan. Jakarta :Salemba Medika.

Setyowati,U.R. 2006. Study of The Postpartum Blues Incident's Factors A Descriptive Research In Maternal Wards I Dr. Soetomo General Hospital Surabaya

Soep. 2009. Pengaruh Intervensi Psikoedukasi Dalam Mengatasi Depresi Postpartum di RSU Dr. Pirngadi Medan. Tesis. http://repository.usu.ac.id/. [2 Desember 2016]

Wijayanti, K. Wijayanti, F.A. Nuryanti, E. 2013. Gambaran faktor-faktor 
resiko postpartum blues di wilayah kerja puskesmas blora. Jurnal kebidanan vol. 2 no. 5.

http://download.portalgaruda.org/.

[17 Oktober 2016] 